\title{
Analysis of Thermal Effects in Infrared and Interference Microscopy: n-Butane-5A and Methanol-Ferrierite Systems
}

\author{
Lars Heinke \\ University of Leipzig
}

Christian Chmelik

ERllvetsthis ofndeipdqitional works at: https://engagedscholarship.csuohio.edu/encbe_facpub

Pavel of the Chemical Engineering Commons
Paveltunov

Uaivessitysoperepsigto this work benefit you? Let us know!

Publisher's Statement

Rranang.ain B Shahe author's version of a work that was accepted for publication in Microporous Cleveland State University

and Mesoporous Materials. Changes resulting from the publishing process, such as peer review, EdBrigg,datrirections, structural formatting, and other quality control mechanisms may not be

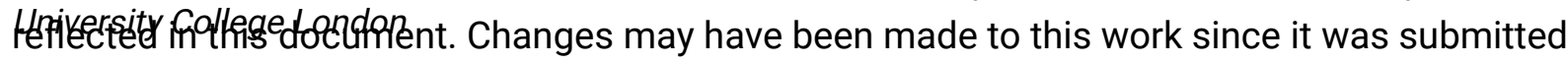
for publication. A definitive version was subsequently published in Microporous and

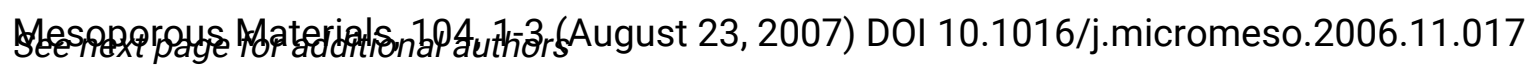

\section{Original Citation}

Heinke, L., Chmelik, C., Kortunov, P., Shah, D., Brandani, S., Ruthven, D., ,...rger, J. (2007). Analysis of thermal effects in infrared and interference microscopy: $n$-Butane-5A and methanol-ferrierite systems. Microporous and Mesoporous Materials, 104(1-3), 18-25. doi:10.1016/j.micromeso.2006.11.017

\section{Repository Citation}

Heinke, Lars; Chmelik, Christian; Kortunov, Pavel; Shah, Dhananjai B.; Brandani, S.; Ruthven, Douglas M.; and Kärger, Jörg, "Analysis of Thermal Effects in Infrared and Interference Microscopy: n-Butane-5A and Methanol-Ferrierite Systems" (2007). Chemical \& Biomedical Engineering Faculty Publications. 66.

https://engagedscholarship.csuohio.edu/encbe_facpub/66

This Article is brought to you for free and open access by the Chemical \& Biomedical Engineering Department at EngagedScholarship@CSU. It has been accepted for inclusion in Chemical \& Biomedical Engineering Faculty Publications by an authorized administrator of EngagedScholarship@CSU. For more information, please contact library.es@csuohio.edu. 


\section{Authors}

Lars Heinke, Christian Chmelik, Pavel Kortunov, Dhananjai B. Shah, S. Brandani, Douglas M. Ruthven, and Jörg Kärger

This article is available at EngagedScholarship@CSU: https://engagedscholarship.csuohio.edu/encbe_facpub/66 


\title{
Analysis of thermal effects in infrared and interference microscopy: $n$-Butane-5A and methanol-ferrierite systems
}

\author{
L. Heinke ${ }^{\text {a }}$, C. Chmelik ${ }^{\text {a,* }}$, P. Kortunov ${ }^{\text {a }}$, D.B. Shah ${ }^{\text {a,b }}$, S. Brandani ${ }^{\text {c }}$, \\ D.M. Ruthven ${ }^{\text {d, J. Kärger }}{ }^{\mathrm{a}}$ \\ ${ }^{a}$ Faculty of Physics and Geosciences, University of Leipzig, Linnestrasse 5, 04103 Leipzig, Germany \\ ${ }^{b}$ Department of Chemical and Biomedical Engineering, Cleveland State University, 2121 Euclid Avenue, Cleveland, OH 44115, USA \\ ${ }^{c}$ Department of Chemical Engineering. University College London, Torrington Place, London WCIE 7JE, UK \\ ' Department of Chemical and Biological Engineering, University of Maine, 5737 Jenness Hall, Orono, ME 04469-5737, USA
}

This paper is dedicated to the memory of Professor Lovat Rees, a pioneer of zeolite research who made many seminal contributions, most recently with respect to the accurate measurement of intracrystalline diffusion by the frequency response method. He was a good friend and a valued colleague. His perceptive comments and unfailing good humour will be sorely missed.

\section{Introduction}

Two recently developed mesoscopic/microscopic techniques have been increasingly applied for the study of diffusion of guest molecules in zeolites. These are infrared microscopy (IRM) and interference microscopy (IFM) methods. These techniques offer the important advantage of being able to monitor concentrations along different locations in the crystal as a function of time. Both methods have the potential to monitor concentration gradients with a fine spatial (within a few microns) and temporal (about $10 \mathrm{~s})$ resolution. As a result, these techniques provide unprecedented insight into various aspects of diffusion in zeolites which the classical macroscopic uptake methods cannot.

IR spectroscopy was first used for studying zeolite diffusion by Niessen and Karge [1]. The technique measures the 
IR absorption spectra of guest molecules present in the crystal. Because of its ability to distinguish between different adsorbates, the IRM can be used for tracer-exchange and co- and counter-diffusion studies [2,3]. The IFM technique was first developed and reported by Schemmert et al. [4]. The technique is based on the principle that the optical density of zeolite crystallites (or other transparent media) depends on the amount and the nature of the guest molecules. As a result, the phase shift between two light beams, one passing through the host crystal under study and the other passing through the surrounding atmosphere, is a measure of the average concentration of guest molecules along the direction of the light beam through the crystal. This mean concentration (i.e., the total amount of molecules in beam direction) may be deduced by analyzing the interference patterns after superposition of these two beams. The potential of the method to shed unprecedented insight into the internal diffusion transport has been recently discussed by Kärger et al. [5].

The IFM method has been successfully used to study micropore diffusion in a variety of zeolites such as ferrierite [6], CrAPO-5 and SAPO-5 [7-10] and MFI [11,12]. The measured concentration profiles in these systems have been used to determine whether the diffusion is one-dimensional, two-dimensional or three-dimensional. It has also been used to determine the existence of surface and internal transport barriers, and internal structural defects. The effect of crystal intergrowths on internal diffusion and the presence of inhomogeneous distribution of guest molecules have been also investigated with IFM. Recently, we have analyzed microscopically the measured concentration profiles of methanol in ferrierite crystals to determine local micropore diffusivities as a function of adsorbate loading [13]. This analysis was performed without relying on specific models and their limitations and the transport parameters were calculated directly by the application of Fick's second law. Such a detailed understanding of micropore diffusion is not possible with the commonly used macroscopic methods.

One important assumption that is made during data analysis in order to calculate micropore diffusivities from the observed profile is that the system is essentially isothermal. One of the main shortcomings of the use of macroscopic methods in the study of zeolite diffusion has been the possibility of intrusion of extraneous heat and mass transfer resistances in the uptake process. It would be ironic if the same criticism were to be leveled at these meso/ microscopic methods. Of course, one advantage these methods have is that measurements are made over individual crystals as against a batch of crystals used in the macroscopic methods. A single crystal has a much higher surface area to volume ratio than that for a batch of crystals and as a result, the increased rate of heat dissipation should be favorable to maintaining constant temperature during these experiments. In this contribution, the isothermal assumption is critically examined with detailed simulations as well as with a more approximate analysis on the basis of time constants. These two analyses both show that non-isothermal effects do not play a significant role in controlling the diffusive transport, at least for the two systems investigated here.

\section{Background}

\subsection{Methods}

The non-isothermal analysis is applied to two systems that have been studied extensively with these techniques: diffusion of $n$-alkanes in $5 \mathrm{~A}$ and methanol in ferrierite crystals. For the analysis of diffusion of $n$-alkanes in $5 \mathrm{~A}$ zeolites, the most severe case of diffusion of butane is considered, as its isotherm is highly nonlinear and rectangular. Moreover, the analysis is also performed for the case of an adsorption step from 0 to 80 mbar and a desorption step from 80 to 0 mbar. The choice of butane as the probe molecule and the size of the pressure step change have been made to simulate severe experimental conditions under which non-isothermal effects could be expected to be significant. The experimental system and the experimental protocol are described in detail elsewhere [13]. A few zeolite crystals are placed in a cuvette $(2 \mathrm{~cm}$ diameter and $0.5 \mathrm{~cm}$ height). The cuvette, made of quartz glass, is attached to a $6 \mathrm{~mm}$ diameter and $150 \mathrm{~mm}$ long tube. It is connected to a flexible stainless steel tubing $(6 \mathrm{~mm}$ diameter and $250 \mathrm{~mm}$ long) by a Swagelok ultra-torr connector. The entire assembly is connected to a Pfeiffer turbo molecular vacuum pump capable of producing vacuum to $10^{-6} \mathrm{mbar}$.

Most experiments with IRM and IFM techniques have been performed with small pressure step changes from 0 to 5 mbar or 10 mbar for adsorption and then from 5 or 10 mbar to 0 mbar representing desorption to vacuum. In the case of ferrierite-methanol system, we have also performed experiments with larger pressure steps for adsorption (0-20, 0-40 and 0-80 mbar) and desorption to vacuum from these pressures $(20-0,40-0$ and $80-0$ mbar). However, as indicated earlier, the simulation has been run for the extreme cases of butane and methanol adsorption/ desorption over the pressure range $0-80$ mbar.

\subsection{Theory of non-isothermal analysis}

For this non-isothermal analysis, it is assumed that diffusion into the zeolite crystals is one-dimensional for both cases and is described by the Fick's second law as given by

$\frac{\partial c}{\partial t}=\frac{\partial}{\partial x}\left(D(c) \frac{\partial c}{\partial x}\right)$

Subject to:

initial condition $c(x, 0)=0$

and boundary conditions $c(-l, t)=c(+l, t)=c_{0}$

Here the local transport diffusivity $D$ is assumed to depend on the local adsorbate concentration. $c_{0}$ is the adsorbate concentration at the surface in equilibrium with the gas 
phase pressure $p$ and $2 l$ is the length of the crystal across which diffusion takes place. The diffusivity, $D$, varies with temperature and this variation is given by the Arrhenius equation $D=D_{0} \cdot \exp \left(-\frac{E_{\mathrm{A}}}{R T}\right)$ where $E_{\mathrm{A}}$ is the activation energy of diffusion and $D_{0}$ is the pre-exponential factor. Adsorption isotherms of methanol on ferrierite and $n$-alkanes on LTA are assumed to be represented by the Langmuir adsorption isotherm $c=c_{\infty} \frac{b \cdot p}{T+b \cdot p}$ with $b=b_{0}$ $\exp \left(f \frac{\Delta H}{R T}\right)$. (Here, $c_{\infty}$ is the maximum amount adsorbed, $\Delta H$ is the heat of adsorption, $b_{0}$ is the pre-exponential constant, $R$ is the universal gas constant and $T$ is the temperature of the system.

The equation for energy transfer is analogous to that for mass transfer with thermal diffusivity $\alpha$ replacing the diffusivity. However, the magnitude of thermal diffusivity is much larger than that for the mass diffusivity

$$
\begin{gathered}
\alpha=\frac{\lambda}{\rho \cdot c_{p}}=\frac{1 \frac{\mathrm{J}}{\mathrm{m} \cdot \mathrm{K} \cdot \mathrm{s}}}{2 \cdot 10^{6} \frac{\mathrm{g}}{\mathrm{m}^{3}} \frac{1.4 \cdot 10^{6} \frac{\mathrm{J}}{\mathrm{m}^{3} \mathrm{~K}}}{2 \cdot 10^{6} \frac{\mathrm{g}}{\mathrm{m}^{3}}}} \approx 7 \cdot 10^{-7} \mathrm{~m}^{2} \mathrm{~s}^{-1} \\
\alpha \gg D \approx 10^{-13} \mathrm{~m}^{2} \mathrm{~s}^{-1}
\end{gathered}
$$

As a result, temperature gradients even out much faster than the concentration gradients. It is, therefore, assumed that the temperature is the same everywhere in the crystal.

The non-isothermal adsorption process with the heat production is represented by a simple heat balance equation given by

$m_{\mathrm{z}} c_{p} \frac{\mathrm{d} T}{\mathrm{~d} t}=(-\Delta H) \frac{\mathrm{d} m}{\mathrm{~d} t}-\frac{\mathrm{d} Q_{\text {loss }}}{\mathrm{d} t}$

Here $c_{p}$ is the heat capacity of zeolite, $m_{\mathrm{z}}$ is the mass of the zeolite crystal and is calculated from its density and volume, $m(t)$ is the total integral amount adsorbed in the zeolite at time $t$ in mol, and $Q_{\text {loss }}$ is the amount of heat lost by the zeolite crystal to the surrounding. The mass of the adsorbate in the crystal at any time can be calculated by integrating the concentration profiles obtained from solution of Eq. (1) at that time. The equation is given by

$m=m_{\mathrm{z}} \iint_{l}^{+l} \frac{c}{2 l} \mathrm{~d} x$

Eq. (3) basically represents the energy balance with the rate of heat gain in the crystal being equal to the difference between the rate of heat evolution due to adsorption and the rate of heat loss by conduction, convection and radiation to the surroundings. If the surroundings represent a quiescent atmosphere, then the heat loss is by radiation and by conduction to the glass surface (due to the contact between the crystal and the cuvette) and to the quiescent atmosphere. The rate of heat dissipation due to radiation is given by the Stefan-Boltzmann law and that by the conductive-convective heat transfer is given by the term $(h A \Delta T)$. The rate of heat loss is then given by

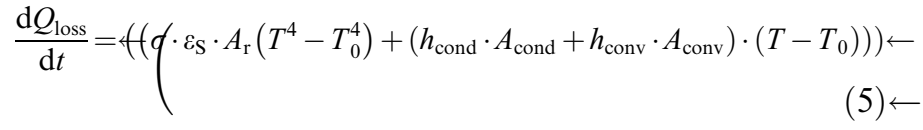

Here $\sigma$ is the Stefan-Boltzmann constant, $\varepsilon_{\mathrm{S}}$ is the surface emissivity, $T_{0}$ is the temperature of the environment, $A_{\mathrm{r}}$ is the area through which the energy radiates away and $A_{\text {cond }}$ is the area over which the crystal is in contact with the glass surface of the optical cell and through which the heat gets conducted away. To ensure that the worst case scenario is considered, we assume here that no heat is transferred by conduction to the cuvette (since this only serves to enhance the heat transfer rate) and we only consider the heat transfer to the surroundings from the crystal by conduction. If the crystal is considered to be an equivalent sphere suspended in a stagnant gas atmosphere, the Nusselt number, $N u=\frac{h d}{k}$ equals 2 [14], where $h$ is the heat transfer coefficient, $d$ is the diameter of the sphere and $k$ is the thermal conductivity of the gas. The thermal conductivity of a gas is essentially independent of pressure over a wide range because it depends on the product of collision frequency $(\propto p)$ and the mean free path $(\propto 1 / p)$ thereby cancelling out the pressure dependence. Constancy of $k$ is generally valid down to the point where the mean free path of gas molecules approaches the dimensions of the container (generally of the order of $1 \mathrm{mbar}$ ). Since both adsorption runs end up with pressures in the cuvette of $80 \mathrm{mbar}, k$ can be assumed constant here.

The above outlined model is sufficiently general since it accounts for dependence of micropore diffusivity on concentration and on temperature, variation of adsorption isotherm with temperature and heats of adsorption associated with adsorption/desorption.

\subsection{Evaluation of parameters}

All parameters necessary for simulation are given in Table 1. The adsorption isotherm of butane on 5A was calculated based on statistical model theory as indicated in [15]

$$
c=\frac{K p+\sum_{m=2}^{m_{\max }} \frac{(K p)^{m}}{(m-n) !}\left(1-\frac{m b}{V}\right)^{m} \exp \left(\frac{m b \varepsilon}{V k_{\mathrm{B}} T}\right)}{1+K p+\sum_{m=2}^{m_{\max }} \frac{(K p)^{m}}{m !}\left(1-\frac{m b}{V}\right)^{m} \exp \left(\frac{m b \varepsilon}{V k_{\mathrm{B}} T}\right)}
$$

Here $K$ is a function of temperature and is given by $K_{0} \exp \left(q_{0} / R T\right)$. The parameters used for $n$-butane-5A system have been given by Ruthven and Loughlin [16] and are summarized here: $m_{\max }=4$ molecules/cavity, $b=$ $202 \AA^{3} /$ molecule, $\quad K_{0}=8.6 \times 10^{-7}$ molecule/(cavity torr), $q_{0}=10.2 \mathrm{kcal} / \mathrm{mol}$ and $\varepsilon / k_{\mathrm{B}}=297 \mathrm{~K}$.

The adsorption isotherm of methanol on ferrierite was obtained from combining our own IRM and IFM measurements and was checked for consistency by comparing with the published data [17]. These data were then fitted to the Langmuir equation to give $c=c_{\infty} \frac{b p^{n}}{\mathrm{f}+b p^{n}}$ with $b=\leftarrow$ $b_{0} \exp \left(-\frac{-\Delta H}{R T}\right)$. Here $c_{\infty}=0.00418 \mathrm{~mol} / \mathrm{g}, b_{0}=1.6 \times 10^{-9}$ $(\mathrm{mbar})^{-1}$ and $-\Delta H$ was assumed to be $40 \mathrm{~kJ} / \mathrm{mol}$. The heat 
Table 1

Parameters used in the simulation calculations

\begin{tabular}{lll}
\hline Property & Butane-5A & Methanol-ferrierite \\
\hline$\Delta H(\mathrm{~kJ} / \mathrm{mol})$ & -32.7 & -40 \\
$E_{\mathrm{A}}(\mathrm{kJ} / \mathrm{mol})$ & 17 & 17 \\
$\varepsilon_{\mathrm{S}}($ surface emissivity) & 0.8 & 0.8 \\
Crystal size $(\mu \mathrm{m})$ & $35 \times 35 \times 35$ & $200 \times 50 \times 10$ \\
$d$, equivalent sphere diameter $(\mu \mathrm{m})$ & 35 & 24 \\
$\rho$, zeolite density $\left(\mathrm{g} / \mathrm{cm}^{3}\right)$ & 2.1 & 1.9 \\
$D_{0}\left(\mathrm{~m}^{2} / \mathrm{s}\right)$ & $1.54 \cdot \exp \left(4.8 \cdot c^{0.75}\right) \cdot 10^{-10}$ & $1.54 \cdot \exp \left(4.8 \cdot c^{0.75}\right) \cdot 10^{-10}$ \\
$b_{0}\left(\mathrm{mbar}^{-1}\right)$ & - & $1.6 \times 10^{-9}$ \\
$c_{\infty}\left(\mathrm{mmol}^{-}\right)$ & 2.247 & 4.18 \\
$\lambda$ of zeolites $(\mathrm{J} /(\mathrm{s} \mathrm{cm} \mathrm{K}))$ & 0.01 & 0.01 \\
$c_{p}$ of zeolites $(\mathrm{J} /(\mathrm{g} \mathrm{K}))$ & 1.4 & 1.4 \\
$\sigma\left(\mathrm{J} /\left(\mathrm{cm}^{2} \mathrm{~s} \mathrm{~K} \mathrm{~K}^{4}\right)\right.$ & $5.67 \times 10^{-8}$ & $5.67 \times 10^{-8}$ \\
$h\left(\mathrm{~J} /\left(\mathrm{cm}^{2} \mathrm{~s} \mathrm{~K}\right)\right)$ & 0.11 & 0.17 \\
$h_{\mathrm{r}}\left(\mathrm{J}\left(\mathrm{cm}^{2} \mathrm{~s} \mathrm{~K}\right)\right)$ & 0.000466 & 0.000466 \\
$k$ of adsorbate $(\mathrm{J} /(\mathrm{s} \mathrm{cm} \mathrm{K}))$ & $1.65 \times 10^{-4}$ & $1.65 \times 10^{-4}$ \\
\hline
\end{tabular}

of adsorption was estimated from the values given in [15] for similar systems.

The concentration dependence of diffusivity of methanol in ferrierite was determined from IFM experiments [13]. For $n$-butane-5A system, the diffusivity increases monotonically with sorbate concentration. However, the corrected diffusivities are essentially independent of concentration [18] and the concentration dependence is due to nonlinearity of equilibrium isotherm. Since the diffusivity of $n$ butane in $5 \mathrm{~A}$ is of the order of $10^{-13} \mathrm{~m}^{2} / \mathrm{s}$ (almost the same as for methanol in ferrierite), we assume the same strong concentration dependence of diffusivity for $n$-butane in $5 \mathrm{~A}$ as for methanol in ferrierite.

The above equations were solved numerically to simulate concentration profiles at different times and calculate the temperature of the crystal as a function of time. Diffusivity variation with concentration and temperature was accounted for and variation of isotherm with changes in temperature was also taken into account.

\section{Results and discussion}

\subsection{Adsorption from 0 to 80 mbar}

During adsorption, the heat of adsorption is released and the temperature of the crystal rises. The increase in crystal temperature affects both the equilibrium isotherm and the diffusivity. The equilibrium amount adsorbed decreases with increasing temperature whereas the diffusivity increases with temperature. The results of simulation for the adsorption step for $n$-butane-5A system are shown in Figs. 1 and 2 and for the methanol-ferrierite system in Figs. 3 and 4.

The strong concentration dependence of the diffusivity is reflected in the form of the concentration profiles shown in Figs. 2 and 4 since, for a constant diffusivity system, the profiles do not show an inflexion.

Figs. 1 and 3 show the temperature of the crystal as a function of time, whereas Figs. 2 and 4 show the comparison

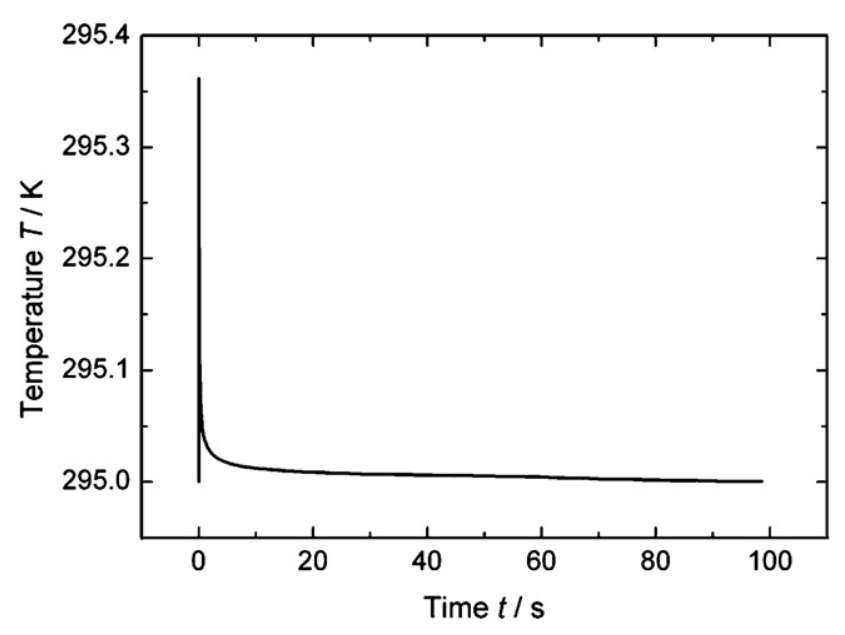

Fig. 1. Temperature versus time for butane adsorption on $5 \mathrm{~A}$ for the pressure step 0-80 mbar. The initial temperature was set to $295 \mathrm{~K}$.

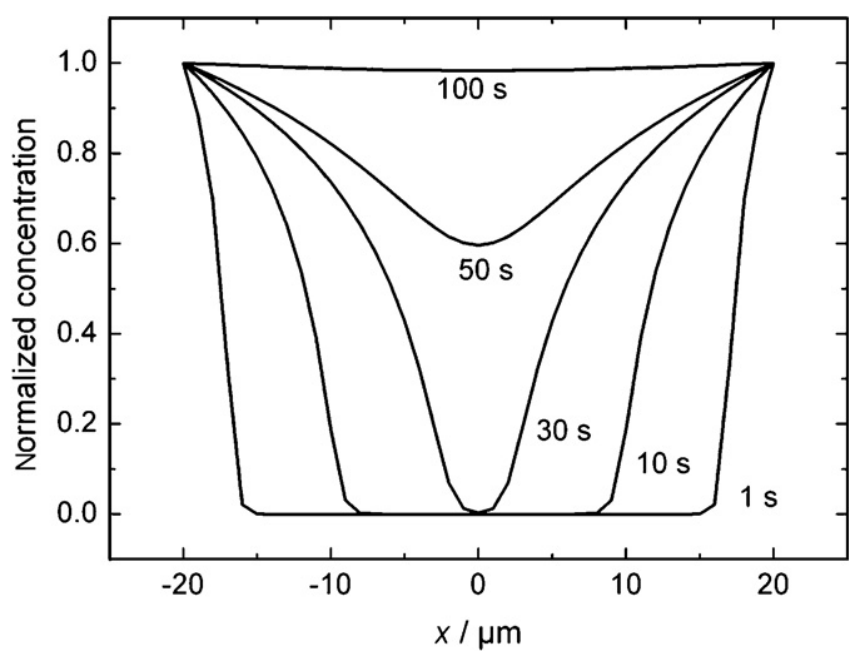

Fig. 2. Simulated concentration profiles for butane adsorption on $5 \mathrm{~A}$ for the pressure step $0-80$ mbar. Solid lines represent simulation results from the isothermal model $(295 \mathrm{~K})$. Dashed lines representing the results from the non-isothermal model cannot be seen as they lie exactly over the isothermal profiles. 


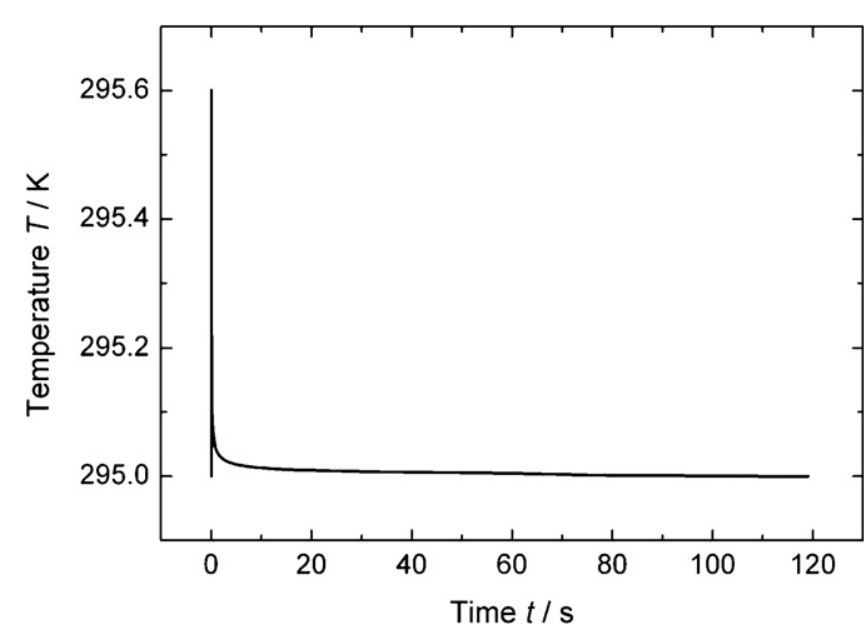

Fig. 3. Temperature versus time for methanol adsorption on ferrierite for the pressure step $0-80$ mbar. The initial temperature was set to $295 \mathrm{~K}$.

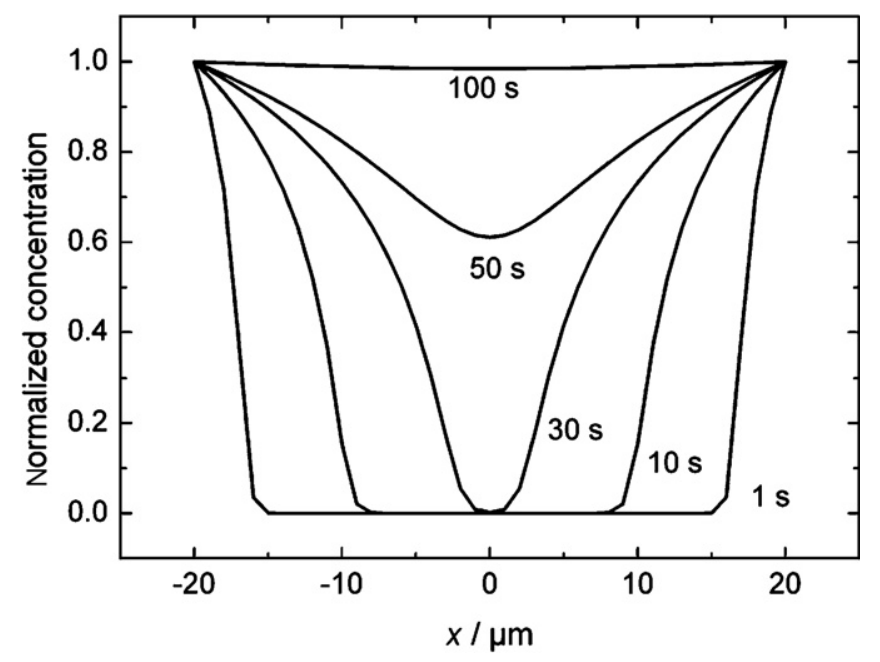

Fig. 4. Simulated concentration profiles for methanol adsorption on ferrierite for the pressure step 0-80 mbar. Solid lines represent simulation results from the isothermal model $(295 \mathrm{~K})$. Dashed lines representing the results from the non-isothermal model cannot be seen as they lie exactly over the isothermal profiles.

between the simulated concentration profiles from the simple isothermal diffusion model and those calculated from the full solution of non-isothermal model. Even for the extreme case of such a large pressure step increase from 0 to $80 \mathrm{mbar}$, the temperature of $5 \mathrm{~A}$ crystal increases only marginally from $295 \mathrm{~K}$ to $295.35 \mathrm{~K}$ almost instantaneously and comes back down to initial temperature almost immediately. The time period associated with this temperature spike is a fraction of a second (Fig. 1). For the methanol-ferrierite system, the temperature rise is just a bit larger (about $0.6 \mathrm{~K}$ ) due to larger value of $c_{\infty}$ and greater heat of adsorption. Again, the temperature changes are accomplished in a fraction of a second (Fig. 3).

The concentration profiles for the case of isothermal and non-isothermal adsorption for both butane-5A and methanol-ferrierite systems are identical. The non-isothermal profiles (dashed lines) are so close to the isothermal profiles (solid lines) that no dashed lines are visible in the figures. The temperature rise in both cases is less than $1 \mathrm{~K}$ and as a result, there is no significant difference between the isothermal and non-isothermal concentration profiles at all times (Figs. 2 and 4). One would expect the non-isothermal profiles to lead the isothermal profiles in reaching the equilibrium conditions. This is because the increase in temperature will slightly increase the diffusivity, which in turn will tend to further even out the concentration profiles. However, it is also important to note that the adsorption process takes much longer to complete (about $2 \mathrm{~min}$ ) compared to the time interval needed for the temperature pulse to disperse through (fraction of a second).

\subsection{Desorption to vacuum}

For the case of desorption to vacuum, the temperature change only affects the diffusivity. Since the final cuvette pressure is effectively zero, the equilibrium concentration will be zero regardless of the temperature of the crystal. Also, during desorption to vacuum, because of the absence of gas phase, there is no conductive heat loss to the surroundings. The only mode of heat transfer is by radiative exchange between the crystal and the surroundings. The results of simulation for desorption to vacuum for $n$-butane-5A system are shown in Figs. 5 and 6 and for the methanol-ferrierite system in Figs. 7 and 8.

Butane desorption produces a cooling of about $3 \mathrm{~K}$ but the temperature recovers to room temperature within $2 \mathrm{~min}$ (Fig. 5). Methanol desorption produces a cooling of about $7 \mathrm{~K}$ but the system regains its original temperature in $2 \mathrm{~min}$ (Fig. 7). Figs. 6 and 8 show the comparison between the isothermal and non-isothermal concentration profiles for butane-5A and methanol-ferrierite systems, respectively. In both cases the two concentration profiles lie close to one another. However, in this case, the non-isothermal profiles (dashed lines) are clearly distinguishable from the

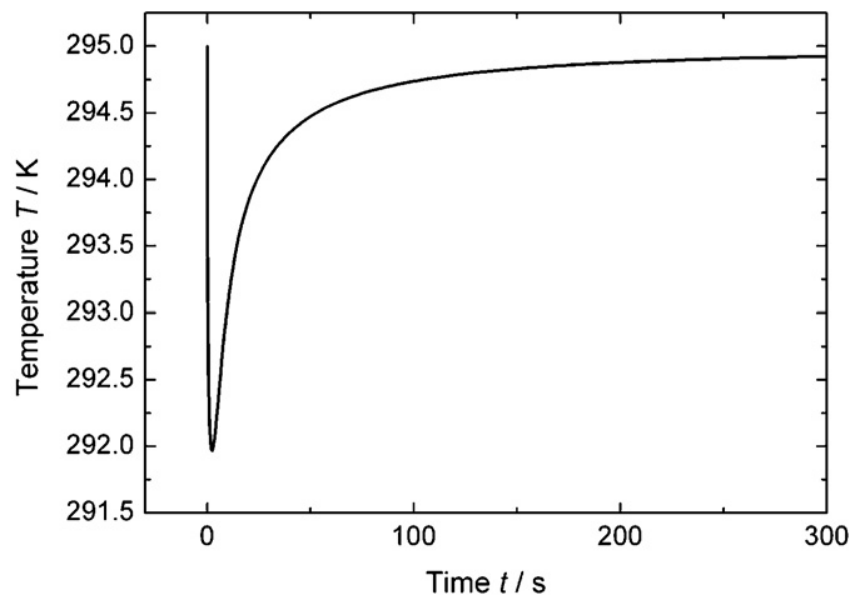

Fig. 5. Temperature versus time for butane desorption from $80 \mathrm{mbar}$ to vacuum on $5 \mathrm{~A}$. The initial temperature was set to $295 \mathrm{~K}$. 


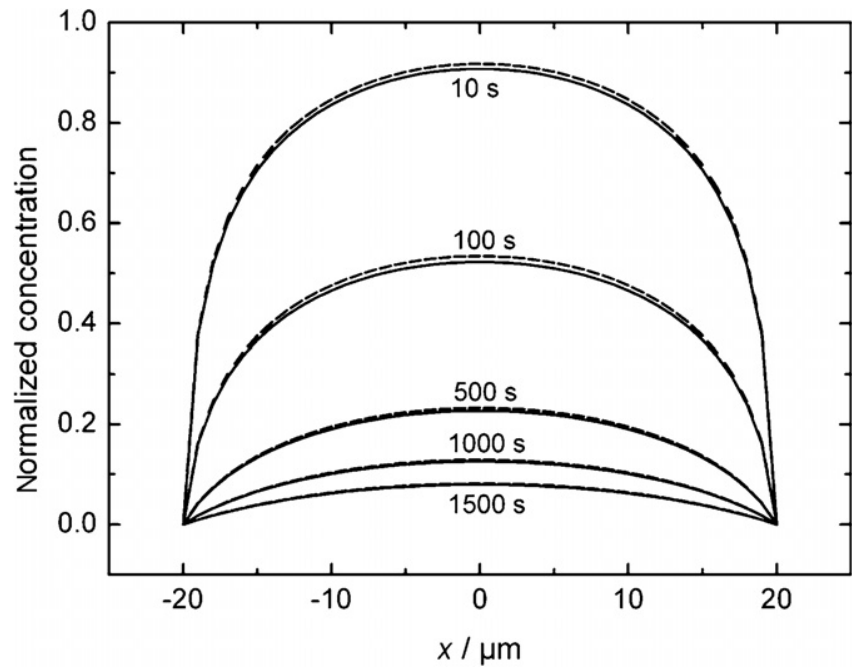

Fig. 6. Simulated concentration profiles for butane desorption from $80 \mathrm{mbar}$ to vacuum in 5A. Solid lines represent the simulation results from the isothermal model $(295 \mathrm{~K})$. Dashed lines represent the results from the non-isothermal model.

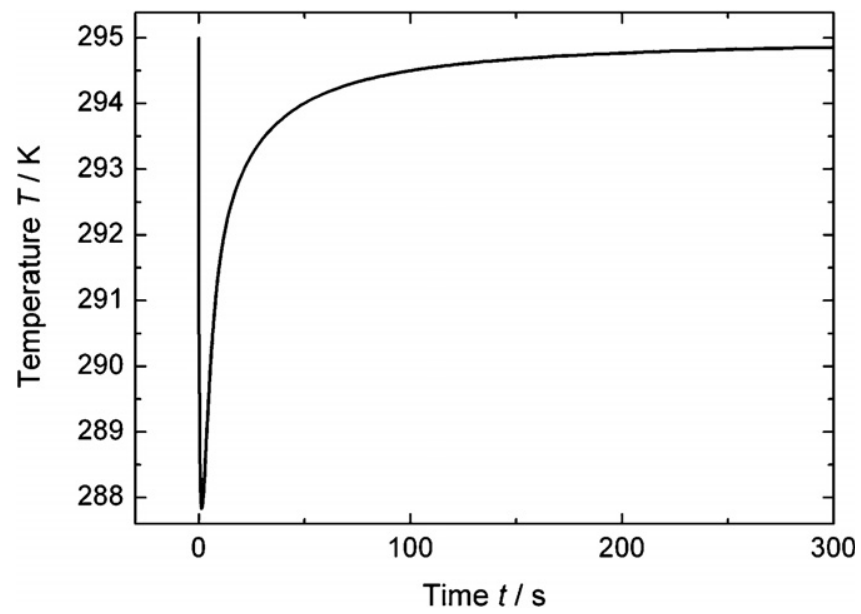

Fig. 7. Temperature versus time for methanol desorption from $80 \mathrm{mbar}$ to vacuum on ferrierite. The initial temperature was set to $295 \mathrm{~K}$.

isothermal profiles (solid lines). As was the case for the adsorption step, the differences between isothermal and non-isothermal concentration profiles are greater for methanol-ferrierite system than for butane-5A system. Moreover, the non-isothermal profiles now lag behind the isothermal profiles in their march towards steady-state conditions. This is easily explained: because of cooling of the crystal, the diffusivity decreases and the concentration profiles take longer to even out. Another interesting feature of the results is that the desorption step is considerably slower than the adsorption step. The entire desorption takes more than $1500 \mathrm{~s}$ compared to about $100 \mathrm{~s}$ for adsorption. This is the result of significant variation of diffusivity with concentration. Diffusivity at the beginning of desorption, where the intracrystalline concentration corresponds to the concentration in equilibrium with the initial pressure of

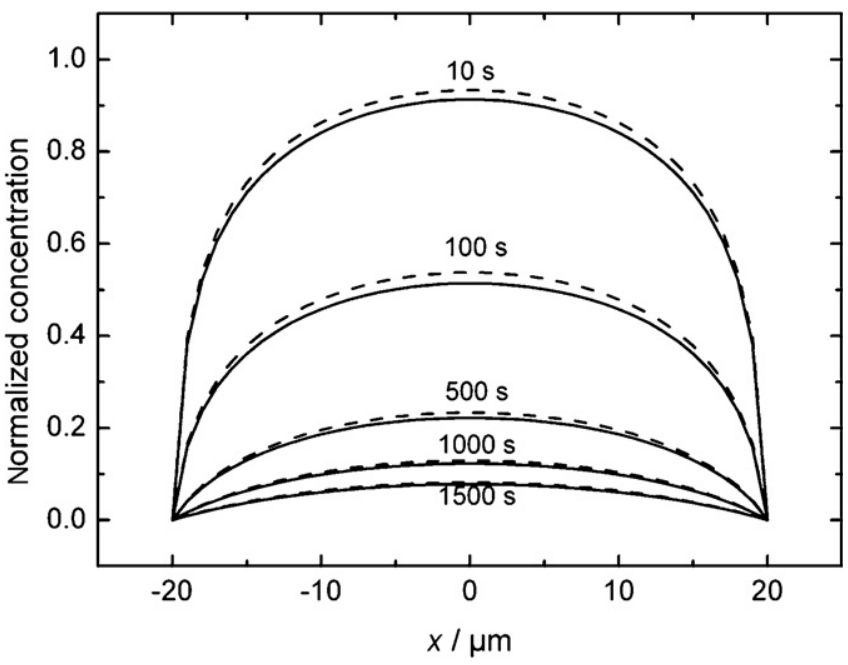

Fig. 8. Simulated concentration profiles for methanol desorption from 80 mbar to vacuum on ferrierite. Solid lines represent the simulation results from the isothermal model $(295 \mathrm{~K})$. Dashed lines represent the results from the non-isothermal model.

80 mbar, is almost two orders of magnitude higher than that at nearly zero loading corresponding to the final pressure of 0 mbar. As a result, the crystal takes much longer to desorb. The reverse argument applies during the adsorption step. The diffusivity at the final loading at $80 \mathrm{mbar}$ is much higher than the value at the initial low pressure, so the crystal reaches equilibrium more rapidly. The large difference between adsorption and desorption rates measured in integral sorption measurements resulting from the concentration dependence of diffusivity has been considered in detail by Garg and Ruthven [19].

\subsection{Approximate analysis}

When there are multiple transport processes taking place simultaneously, an analysis based on the evaluation of time constants for each of the transport processes provides an easy way to gauge the relative importance of each transport process. In the present case, we have diffusive transport occurring within the crystal and simultaneously, heat transfer occurring to the surroundings. The other transport process, heat conduction within the crystal, was proved by a similar order of magnitude analysis to be too fast. Two limiting cases are worthy of interest

$\tau_{\text {heat transfer }} \tau_{\text {diffusive transfer }}$

In this case, time required to dissipate heat is much greater than the time for diffusive transfer. In other words, diffusive transport is much more rapid than the heat transfer. Physically, the concentration gradients will even out much more rapidly than the temperature gradients. Under such a scenario, the crystal can be considered to have uniform concentration over its volume and the limiting transport will be the rate of heat loss to the surroundings

$\tau_{\text {heat transfer }} \ll \tau_{\text {diffusive }}$ transfer 
Table 2

Estimated time constants for butane-5A and methanol-ferrierite systems

\begin{tabular}{lllllc}
\hline Step & Butane-5A & & & Methanol-ferrierite \\
\cline { 2 - 3 } & $\tau_{\text {heat transfer }}(\mathrm{s})$ & & & $\tau_{\text {heat transfer }}(\mathrm{s})$ & 3 \\
\hline Adsorption & 0.015 & 3 & 0.0063 & $\tau_{\text {diffusive transfer }}(\mathrm{s})$ \\
Desorption to vacuum & 3.5 & 260 & 2.3 & 260 \\
\hline
\end{tabular}

This scenario represents a case where the time constant for the diffusive transport is much greater than the time constant for the heat transfer. In such a case, heat transfer is so much more rapid than the mass transfer that for all the practical purposes, the diffusive transport process may be considered to occur at a constant temperature

$\tau_{\text {heat transfer }} \tau_{\text {diffusive transfer }}$

In such cases, both time constants are of comparable value and hence neither the heat transfer nor the diffusive transport is limiting and both processes have to be taken into account.

Time constant for diffusion is generally taken as $\frac{R^{2}}{15 D}(\mathrm{Eq}$. (9.82) of [18]). The time constant for the heat transfer may be estimated by $\frac{m_{z} c_{p}}{h A}$ (Eq. (9.61) of [18]). Based on these expressions, the time constants for both systems have been calculated for both cases of adsorption and desorption to vacuum and are given in Table 2.

The approximate analysis based on the magnitude of time constants confirms the results obtained by the more accurate simulation. The time constants for heat transfer during the adsorptive step are much smaller (by 3-4 orders of magnitude) than those for the diffusive transport. As a result, one should expect essentially an isothermal operation. This is borne out by the results from the simulation (Figs. 1-4). However, for the case of desorption, even though the heat transfer time constant is still smaller than that for the diffusive transfer, the two time constants are now within 2 orders of magnitude. For desorption, therefore, temperature effects are more important than for adsorption.

There is some uncertainty associated with calculating the time constant for diffusion because the diffusivity changes by more than two orders of magnitude over the concentration range. In our computations for diffusive time constants, we have used the value of diffusivity at the final pressure value (at 80 mbar for adsorption and at 0 mbar for desorption). In spite of this uncertainty, heat transfer time constants are smaller than the diffusion time constants for both systems. This indicates that the process of heat transfer proceeds much faster than mass transfer and hence the adsorption and desorption steps can be treated essentially as isothermal.

\section{Conclusions}

Data analysis of measurements made with IRM and IFM involving individual crystals can be performed assuming isothermal conditions. The temperature change produced during adsorption is negligible because of the high rate of conductive heat transfer to the surrounding. For desorption to a vacuum, the rate of heat dissipation decreases substantially since the only mode of heat transfer is by radiation which is about three-order of magnitudes smaller than the conductive heat transfer. The temperature change predicted for this step was higher (3-7 K). However, room temperature was still regained relatively rapidly in comparison with the time scale of the desorption experiments. Even though the analysis was performed for two specific systems, because of the extreme scenario considered here, similar conclusions appear likely for any system.

\section{Acknowledgments}

Financial support provided by Deutsche Forschungsgemeinschaft (Gast-Mercator award to D.B.S., International Research Group "Diffusion in Zeolites"), Fonds der Chemischen Industrie and Max-Buchner-Forschungsstiftung is gratefully acknowledged.

\section{References}

[1] W. Niessen, H.G. Karge, Micropor. Mater. 1 (1993) 1.

[2] H.G. Karge, W. Niessen, H. Blundau, Appl. Catal. A: Gen. 146 (1996) 339

[3] M. Hermann, W. Niessen, H.G. Karge, Stud. Surf. Sci. Catal. 94 (1995) 131

[4] U. Schemmert, J. Kärger, J. Weitkamp, Micropor. Mesopor. Mater. 32 (1999) 101

[5] J. Kärger, P. Kortunov, S. Vasenkov, L. Heinke, D.B. Shah, R.A. Rakoczy, Y. Traa, J. Weitkamp, Angew. Chem. Int. Ed. 45 (2006) 7846.

[6] P. Kortunov, C. Chmelik, J. Kärger, R.A. Rakoczy, D.M. Ruthven, Y. Traa, S. Vasenkov, J. Weitkamp, Adsorption 11 (2005) 235.

[7] C. Chmelik, P. Kortunov, S. Vasenkov, J. Kärger, Adsorption 11 (2005) 455

[8] E. Lehmann, C. Chmelik, H. Scheidt, S. Vasenkov, B. Staudte, J. Kärger, F. Kremer, G. Zadrozna, J. Kornatowski, J. Am. Chem. Soc. 124 (2002) 8690.

[9] E. Lehmann, S. Vasenkov, J. Kärger, G. Zadrozna, J. Kornatowski, J. Chem. Phys. B 118 (2003) 6129.

[10] E. Lehmann, S. Vasenkov, J. Kärger, G. Zadrozna, J. Kornatowski, Ö. Weiss, F. Schüth, J. Phys. Chem. B 107 (2003) 4685.

[11] O. Geier, S. Vasenkov, E. Lehmann, J. Kärger, U. Schemmert, R.A. Rakoczy, J. Weitkamp, J. Phys. Chem. B 105 (2001) 10217.

[12] P. Kortunov, S. Vasenkov, C. Chmelik, J. Kärger, D.M. Ruthven, J. Wloch, Chem. Mater. 16 (2004) 3552.

[13] P. Kortunov, L. Heinke, S. Vasenkov, C. Chmelik, D.B. Shah, J. Kärger, R.A. Rakoczy, Y. Traa, J. Weitkamp, J. Phys. Chem. B 110 (2006) 23821. 
[14] R.B. Bird, W.E. Stewart, E.N. Lightfoot, Transport Phenomena, Wiley, New York, 1960.

[15] D.M. Ruthven, Fundamentals of Adsorption and Adsorption Processes, Wiley, New York, 1984, pp. 34 44, 101-104.

[16] D.M. Ruthven, K.F. Loughlin, Trans. Faraday Soc. 68 (1972) 692.
[17] Y. Long, M. Ma, Y. Sun, H. Jiang, J. Inclus. Phenom. Macrocycl. Chem. 37 (2000) 103.

[18] J. Kärger, D.M. Ruthven, Diffusion in Zeolites and Other Microporous Solids, Wiley, New York, 1992.

[19] D.R. Garg, D.M. Ruthven, Chem. Eng. Sci. 27 (1972) 417. 